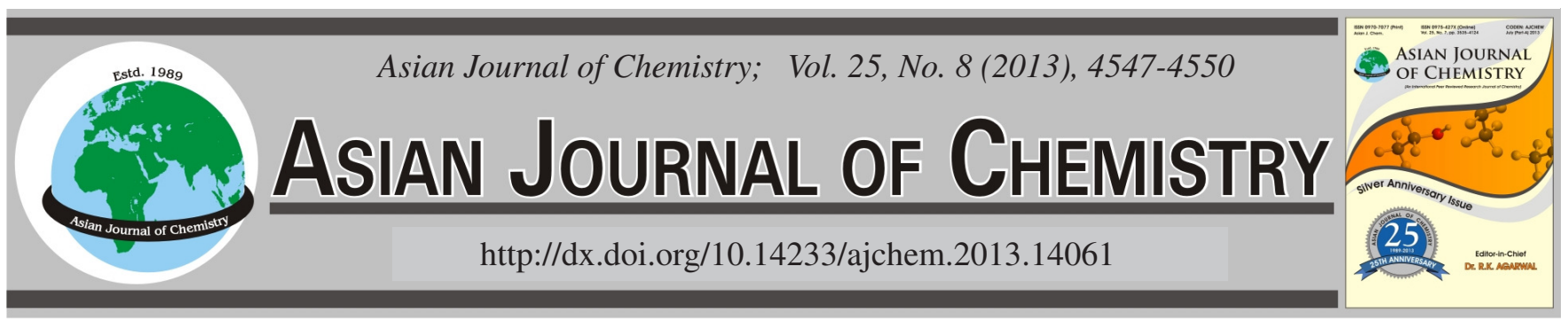

\title{
Determination of Gossypol in Poultry Egg and Feed by Automated Solid- Phase Extraction and High-Performance Liquid Chromatography
}

\author{
Zu-Hao Shi, Meng-Jun Tang, Xiao-Yan Zhang, Zhi-Yun Tao, Ming Wu, \\ Yu-Shi GaO*, Rong Gu, Jun-Xian Lu, Jun-hua Pu and Qing-Lian Ge
}

Quality Inspection Center for Poultry of Ministry of Agriculture, Poultry Institute, Chinese Academy of Agricultural Sciences, Yangzhou 225003, P.R. China

*Corresponding author: E-mail: vetszh@gmail.com

\begin{abstract}
A high-performance liquid chromatographic method for the determination of gossypol in poultry egg and feed was developed. Gossypol was extracted with $90 \%$ acetonitrile/water (v/v) in presence of ascorbic acid and purified by $\mathrm{C}_{18}$ cartridge with automated solid-phase extraction system. The samples were separated through an optimized chromatography condition on a $\mathrm{C}_{18}$ column $(4.6 \mathrm{~mm} \times 250 \mathrm{~mm}, 5$ $\mu \mathrm{m}$ particle) and UV detection at $235 \mathrm{~nm}$. A gradient with acetonitrile and water containing $0.1 \%$ phosphoric acid was applied. The method was shown to be highly reproducible, with overall recovery was $89.5 \%$ and relative standard deviation was $8.7 \%$.

Key Words: Gossypol, High-performance liquid chromatography, Egg, Poultry feed.
\end{abstract}

\section{INTRODUCTION}

Gossypol (1,1',6,6', 7,7'-hexahydroxy-5,5'diisopropyl-3,3'dimethyl[2,2']binaphthalene[8,8']dicarboxaldehyde) is a yellow, polyphenolic compound found primarily in the pigment glands that are distributed throughout the cotton plants (Gossypium sp.). Gossypol (Fig. 1) has been known to have toxic effects on terrestrial animals ${ }^{1}$, humans ${ }^{2}$ and fish ${ }^{3-5}$. Gossypol, it also has been reported that associated with a wide range of biological and medicinal activity, including antitumor $^{6-9}$, antifertility ${ }^{10-13}$ and antiviral ${ }^{14,15}$ effects.<smiles>Cc1cc2c(C(C)C)c(O)c(O)c(C=O)c2c(O)c1-c1c(C)cc2c(C(C)C)c(O)c(O)c(C=O)c2c1O</smiles>

Fig. 1. Chemical structures of gossypol

There are several methods to determine gossypol, such as spectrophotometry ${ }^{16,17}$, gas chromatography ${ }^{18}$ and highperformance liquid chromatography ${ }^{19-22}$. Each of these methods can reflect the relative levels of gossypol. However, the chemical methods are not very specific and gossypol analogs give positive values resulting into significant overes- timation. Gossypol is an involatile chemical compound that can't be analyted by gas chromatography directly. For the gossypol is easily oxidized which has six hydroxyl groups and two aldehyde groups, the derivatived of gossypol is difficult. McClure ${ }^{18}$ has reported a gas-liquid chromatography method of gossypol trimethylsilyl derivatives, but the gossypol molecule is incomplete silyation. In contrast, the HPLC method is more accurate, effective and specialized.

The determination of gossypol in animal tissues by HPLC method has been reported by some researchers ${ }^{21-24}$, but these methods were lacked efficacious cleanup procedure that is difficult to quantitative determination of low concentration of gossypol.

Following feeding to animals, gossypol is absorbed from the digestive tract and retained in the tissues where it ocurrs in both the free and protein-bound form appears particularly high concentrations in pigs ${ }^{25}$, ovine ${ }^{24}$ and trout ${ }^{26,27}$. High gossypol concentrations in animal tissues may represent a concern for public health. Recently, in China, a series of case reports about a large quantity of faked eggs were made and sold to people to eat from Chinese newspapers, magazines and the Internet ${ }^{28}$. However, according to our investigation, these eggs are not man-made fake eggs, the reason for this is the using of cottonseed meal in hen feed as protein source. Thus, there has been increasing interests in the development a more reliable method for the determination of gossypol in eggs. 


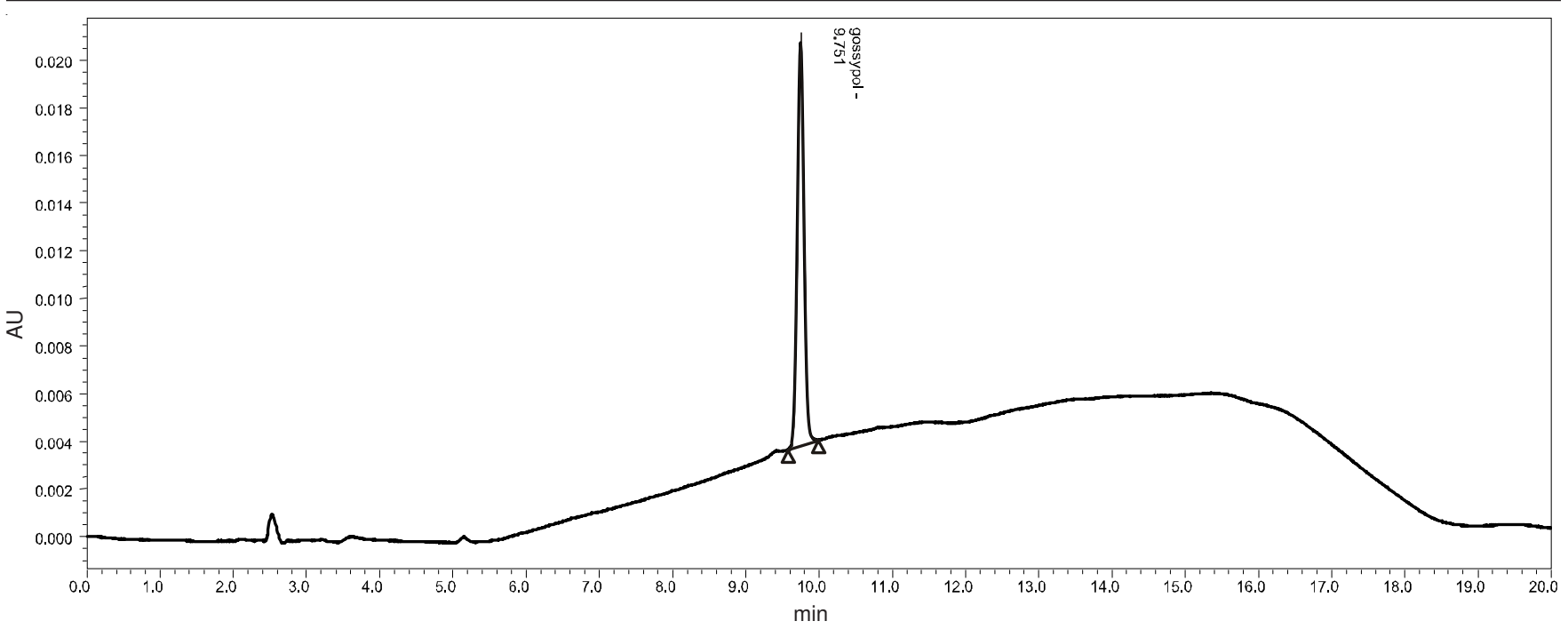

Fig. 2. Chromatogram of $0.5 \mu \mathrm{g} \mathrm{mL^{-1 }}$ gossypol standard solution

This paper describes a high-performance liquid chromatography method that has been developed for the determina tion of gossypol in poultry egg and feed.

\section{EXPERIMENTAL}

Water was purified via Milli-Q (Millipore, Bedford, MA, USA). Acetonitrile and methanol (HPLC grade) were obtained from Merck (Darmstadt, Germany), Analytical-grade ascorbic acid, acetonitrile, hydrochloric (37\% min.), potassium dihydrogen phosphate and phosphoric acid were obtained from Sinopharm Chemical Reagent Co. Ltd., (Shanghai, China). Gossypol from Sigma-Aldrich Co. (St Louis, Mo, USA). A gossypol stock solutions $(0.5 \mathrm{mg} / \mathrm{mL})$ was prepared by dissolving $25 \mathrm{mg}$ of gossypol in $50 \mathrm{~mL}$ of acetonitrile. Aliquots of these solutions were further diluted with acetonitrile to give working solutions that contained pure gossypol in the range 0.1-10 $\mu \mathrm{g} / \mathrm{mL}$. Working solutions were prepared daily and protected from light throughout the analysis.

Analysis by high-performance liquid chromatography was performed using an Alliance 2695 HPLC (Waters, Milford, MA, USA) equipped with a vacuum degasser, a quaternary gradient pump, a heated column compartment and a UV detector. The chromatographic separation was carried out on a symmetry ${ }^{\circledR} \mathrm{C}_{18}$ column $(250 \mathrm{~mm} \times 4.6 \mathrm{~mm})$ with $5 \mu \mathrm{m}$ particle size. Injection volume was $20 \mu \mathrm{L}$ and eluent flow rate was $1.0 \mathrm{~mL} / \mathrm{min}$. A detection wavelength was $235 \mathrm{~nm}$. Column temperature was set at $30^{\circ} \mathrm{C}$. A gradient was applied with water containing $0.1 \%$ phosphoric acid (A) and methanol (B). The gradient conditions were as follows: begin with $80 \% \mathrm{~B}$, hold for $2 \mathrm{~min}$; from 2 to $9 \mathrm{~min}$ ramp from 80 to $98 \% \mathrm{~B}$; hold for $4 \mathrm{~min}$; ramp over $2 \mathrm{~min}$ to $80 \% \mathrm{~B}$; hold for $5 \mathrm{~min}$ to re-equilibrate the system.

Sample preparations: A 2 g samples of egg or a $5 \mathrm{~g}$ samples of feed was mixed with $20 \mathrm{~mL}$ extraction reagent composed of $90 \%$ acetonitrile/water $(\mathrm{v} / \mathrm{v})$ in presence of $3 \%$ (w/v) ascorbic acid and vigorously vortexed (VTX-3000L, Japan). The vortexed samples were shaked with HS 501 reciprocating oscillator ( $\mathrm{GmbH} \& \mathrm{CO} . \mathrm{KG}$, Germany) for 30 min and then centrifuged $\left(4^{\circ} \mathrm{C}\right.$ ) at $10000 \mathrm{rpm}$ for $5 \mathrm{~min}$ (Hitachi
CR22G, Japan). After centrifuged, the supernatant was transferred to a $50 \mathrm{~mL}$ pear-shaped bottle and added $5 \mathrm{~mL}$ isopropanol, then evaporated to $2-3 \mathrm{~mL}$ at $40^{\circ} \mathrm{C}$ on the R-210 rotary evaporator (Buchi Labortechnik AG, Switzerland). Residues was diluted with $10 \%$ phosphoric acid solution to $10 \mathrm{~mL}$ volume.

The sample clean-up is performed on automated solid phase extraction system (GX-274 ASPEC, Gilson, USA), Bond Elut $\mathrm{C}_{18}$ column $(500 \mathrm{mg} / 3 \mathrm{cc}$, Varian Inc.) was conditioned with $3 \mathrm{~mL}$ of acetonitril and $3 \mathrm{~mL}$ of water. Loaded $10 \mathrm{~mL}$ of the sample extract and washed the column with $3 \mathrm{~mL}$ of water and $2 \mathrm{~mL} 20 \%$ acetonitrile/water (v/v), then eluted the column with $2 \mathrm{~mL}$ of acetonitrile. The eluted solvents were filtered with $0.22 \mu \mathrm{m}$ membranes and subjected to HPLC-UV analysis.

\section{RESULTS AND DISCUSSION}

Chromatographic separation and detection: At the initial of experiment, the HPLC conditions of gossypol was performed under isocratic elution using a mobile phase of methanol-water $(88: 12$, v/v) containing $0.1 \%$ of phosphoric acid. However, the peak tailing was serious even though the concentration of phosphoric acid was increased to $0.3 \%$. Therefore, to improve the resolution, a gradient elution program was used. First, $80 \%$ methanol was used to elute the less retaining compounds and a rapid linear gradient to $98 \%$ methanol at $9 \mathrm{~min}$, followed by an isocratic run $80 \%$ methanol to equilibrate the chromatographic column for next running. Gossypol was eluted at 9.4 min with a perfect peak shape (Fig. 2).

The linearity of the UV response was proved seven calibration pionts in the concentration range $0.1-50 \mu \mathrm{g} / \mathrm{mL}$, the determination coefficients $\left(\mathrm{R}^{2}\right)$ of the standard curves were at least 0.9998 .

Optimization of the sample preparation procedure: As gossypol is easily oxidized in aqueous solution, attempts were made to protect the compound against oxidative degradation from the beginning of sample handling. Wang et al. ${ }^{29}$ reported that a considerable loss of gossypol in human plasma kept at $0{ }^{\circ} \mathrm{C}$ for $6 \mathrm{~h}$ occurs unless reduced glutathione is added. A series of pertinent experiments with liver samples showed that 
addition of $3 \%$ of ascorbic acid to the extraction solvent could efficiently protect gossypol, increasing its recovery from $10 \%$ to more than $80 \%$.

The extraction of gossypol from egg samples was carried out with $90 \%$ acetonitrile/water, a solvent which effectively precipitates proteins. These observations concur with other researchers ${ }^{23,29}$, who also used acetoniltrile for deproteinization purposes in the determination of gossypol in human plasma and Botsoglou ${ }^{23}$ for deproteinization purposes in the determination of gossypol in chicken liver. The proportion of acetonitril is significant for the recovery of gossypol, less than $70 \%$, the recovery is less than $60 \%$, at $90 \%$, the recovery is $95 \%$ approximately.

As gossypol has a very high retention on $\mathrm{C}_{18}$ column, purification of the protein-free filtrates was performed by through the Bond-Elut $\mathrm{C}_{18}$ cartridge and eluted with acetonitrile. The result is shown in Fig. 3. Under the mentioned conditions, gossypol could be determined in egg at levels down to 0.1 ppm. At the former, we used methanol as elute solution. The results showed that gossypol is not stable in the methanol solution.

Validation study: Since no certified reference material was available, the exactness of the result was proved with recovery. Precision was proved with repeatability. Blank eggs for validation experiments were obtained by analyzing eggs bought at different supermarkets and presented by layer farms of Poultry Institute, Chinese Academy of Agricultural Sciences. Finally blank eggs were obtained from a layer farm. Blank feed samples were obtained from layer farm too. For the recovery, known amounts of gossypol standards in extract reagent solution were added into running samples at the beginning of the extraction and followed by the same procedure as described before. Six replicates of known gossypol negative sample were spiked at 0.5, 2.5, $10 \mathrm{ppm}$ with gossypol for egg samples and 5, 20, 50 ppm for poultry feed samples. External standard curve of gossypol was prepared with the concentration from 0.1 to $50 \mu \mathrm{g} / \mathrm{mL}$. The concentration of gossypol in the samples was calculated by reference to this external standard curve.

Detailed results are presented in Tables 1 and 2. For egg samples, an overall recovery of $89.8,92.0$ and $91.6 \%$ for the concentration levels $0.5,5$ and $20 \mathrm{ppm}$ was obtained. For poultry feed samples, recovery for the concentration levels 5 , 20 and 50 ppm was $92.2,90.9$ and $92.8 \%$, respectively. The within-day precision was found to be from 1.1 to $6.5 \%$ and the between-days precision 1.6 to $5.9 \%$, respectively.

\section{Conclusion}

The experimental work reported in this article has been aimed to develop a relatively fast HPLC method for the detection of gossypol in poultry egg and feed. The samples only pass
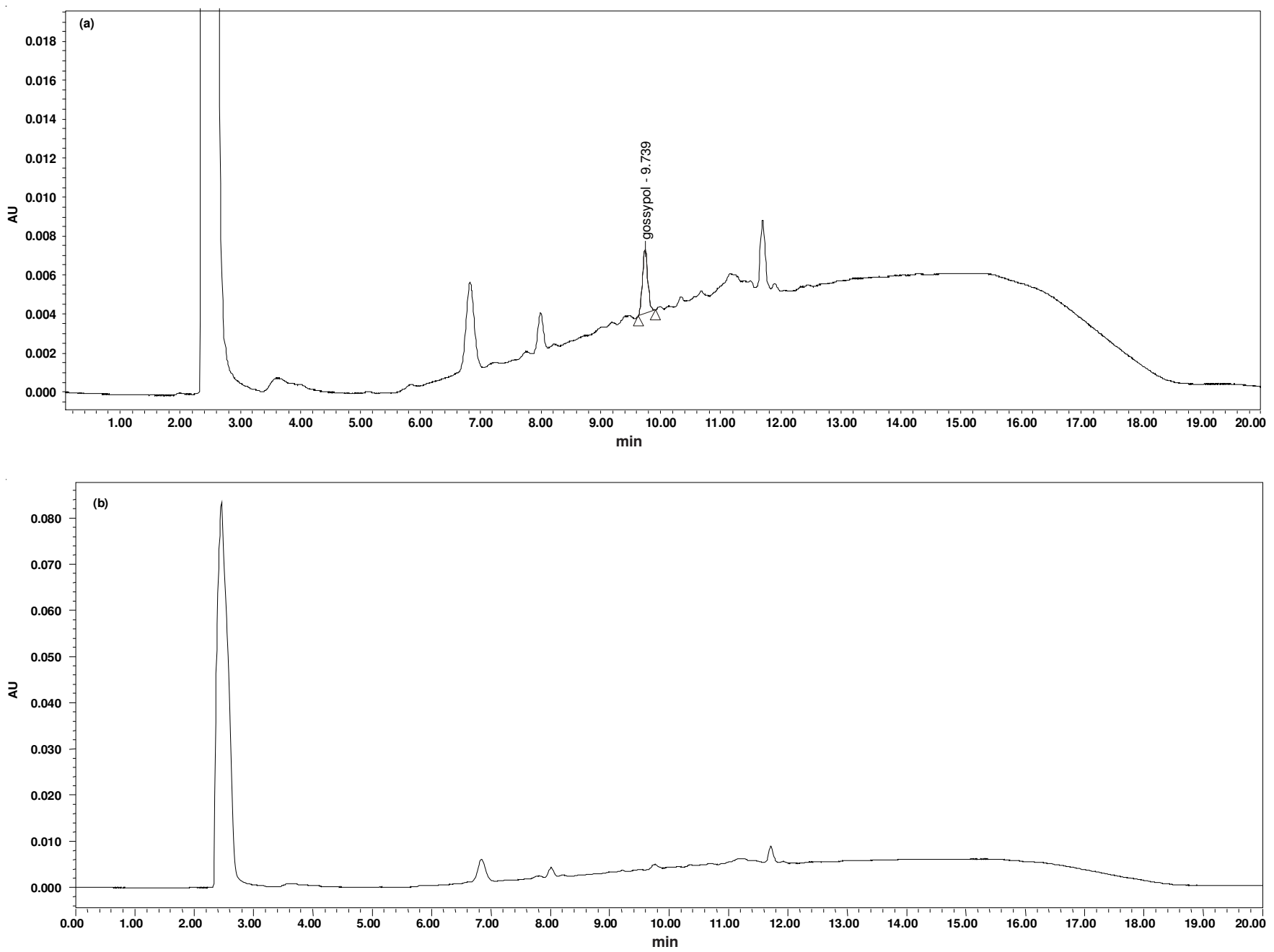

Fig. 3. Typical chromatogram of egg sample spiked 0.5 ppm (a) and blank (b) 


\begin{tabular}{|c|c|c|c|c|}
\hline \multicolumn{5}{|c|}{$\begin{array}{c}\text { TABLE-1 } \\
\text { DETAILED RESULTS OF THE INNER-AND } \\
\text { INTRA-DAY PRECISION AND RECOVERY } \\
\text { EXPERIMENTS FOR EGG SAMPLE }\end{array}$} \\
\hline & Day1 & Day2 & Day3 & Overall \\
\hline \multicolumn{5}{|l|}{$0.5 \mathrm{mg} / \mathrm{kg}$} \\
\hline $\mathrm{n}$ & 6.00 & 6.00 & 6.00 & 18.00 \\
\hline Mean $\left(\mathrm{mg} \mathrm{kg}^{-1}\right)$ & 0.43 & 0.46 & 0.46 & 0.45 \\
\hline $\mathrm{s}\left(\mathrm{mg} \mathrm{kg}^{-1}\right)$ & 0.02 & 0.03 & 0.02 & 0.02 \\
\hline $\mathrm{RSD}(\%)$ & 4.50 & 6.33 & 5.32 & 5.38 \\
\hline Mean recovery $(\%)$ & 86.33 & 91.00 & 92.00 & 89.78 \\
\hline \multicolumn{5}{|l|}{$5 \mathrm{mg} / \mathrm{kg}$} \\
\hline $\mathrm{n}$ & 6.00 & 6.00 & 6.00 & 18.00 \\
\hline Mean $\left(\mathrm{mg} \mathrm{kg}^{-1}\right)$ & 4.79 & 4.21 & 4.80 & 4.60 \\
\hline $\mathrm{s}\left(\mathrm{mg} \mathrm{kg}^{-1}\right)$ & 0.07 & 0.15 & 0.07 & 0.10 \\
\hline $\operatorname{RSD}(\%)$ & 1.41 & 3.53 & 1.53 & 2.16 \\
\hline Mean recovery $(\%)$ & 95.83 & 84.17 & 96.00 & 92.00 \\
\hline \multicolumn{5}{|l|}{$20 \mathrm{mg} / \mathrm{kg}$} \\
\hline $\mathrm{n}$ & 6.00 & 6.00 & 6.00 & 18.00 \\
\hline Mean $\left(\mathrm{mg} \mathrm{kg}^{-1}\right)$ & 18.63 & 18.28 & 18.06 & 18.32 \\
\hline $\mathrm{s}\left(\mathrm{mg} \mathrm{kg}^{-1}\right)$ & 0.51 & 0.37 & 0.20 & 0.36 \\
\hline $\operatorname{RSD}(\%)$ & 2.74 & 2.02 & 1.12 & 1.96 \\
\hline Mean recovery (\%) & 93.16 & 91.38 & 90.32 & 91.62 \\
\hline
\end{tabular}

(S016) and the Science Foundation of Yangzhou (2008040), National Scientific and Technological Support Project (2012BAD39B04).

\section{REFERENCES}

1. J. Colin-Negrete, H.E. Kiesling, T.T. Ross and J.F. Smith, J. Dairy Sci., 79, 2016 (1996).

2. S.Z. Qian and Z.G. Wang, Ann. Rev. Pharmacol. Toxicol., 24, 329 (1984).

3. R.L. Herman, J. Fish Biol., 2, 293 (1970).

4. J. Rinchard, A. Ciereszko, K. Dabrowski and J. Ottobre, Toxicol. Lett., 111, 189 (2000).

5. K. Dabrowski, J. Rinchard, K.-J. Lee, J.H. Blom, A. Ciereszko and J. Ottobre, Biol. Reprod., 62, 227 (2000).

6. C. Van Poznak, A.D Seidman, M.M. Reidenberg, M.M. Moasser, N. Sklarin, K. Van Zee, P. Borgen, M. Gollub, D. Bacotti, T.J.Yao, R. Bloch, M. Ligueros, M. Sonenberg, L. Norton and C. Hudis, Breast Cancer Res Treat., 66, 239 (2001).

7. M.J. Sikora, J.A. Bauer, M. Verhaegen, T.J. Belbin, M.B. Prystowsky, J.C. Taylor, J.C. Brenner, S. Wang, M.S. Soengas, C.R. Bradford and T.E. Carey, Cancer Biol. Ther., 7, 767 (2008).

8. M.D. Shelley, L. Hartley, P.W. Groundwater and R.G. Fish, Anticancer Drugs., 11, 209 (2000).

9. G.P. Tuszynski and G. Cossu, Cancer Res., 44, 768 (1984).

10. A.S. El-Sharaky, M.M. Wahby, M.M. Bader El-Dein, R.A. Fawzy and I.N. El-Shahawy, Food Chem. Toxicol., 47, 2735 (2009).

11. P.M. Zavos and P.N. Zarmakoupis-Zavos, Tohoku J. Exp. Med., 179, 167 (1996)

12. K. Dabrowski, K.J. Lee, J. Rinchard, A. Ciereszko, J.H. Blom and J.S. Ottobre, Biochim. Biophys. Acta, 1525, 37 (2001).

13. M. Nakamura, M. Ikeda, M. Komukai, T. Suyemitsu, S. Okinaga and K. Arai, Hum Reprod., 6, 714 (1991).

14. B. Polsky, S.J. Segal, P.A. Baron, J.W. Gold, H. Ueno and D. Armstrong, 39, 579 (1989).

15. K. Ratsula, M. Haukkamaa, K. Wichmann and T. Luukkainen, Contraception, 27, 571 (1983).

16. L. Qin, X.J. Shen, J.H. Chen and S.J. Zhu, Guang Pu Xue Yu Guang Pu Fen Xi, 30, 635 (2010).

17. N.A. Botsoglou and D.C. Kufidis, J. Assoc. Off. Anal. Chem., 73, 447 (1990).

18. M.A. McClure, J. Chromatogr. A, 54, 25 (1971).

19. G.B. Marcelle, M.S. Ahmed, J.M. Pezzuto, G.A. Cordell, D.P. Waller, D.D. Soejarto and H.H. Fong, J. Pharm. Sci., 73, 396 (1984).

20. K.J. Lee, K. Dabrowski, J. Chromatogr. B: Anal. Technol. Biomed. Life Sci., 779, 313 (2002).

21. X. Cui, C. Xie, L. Zhang and Z. Jin, Se Pu, 22, 559 (2004).

22. R. Meyer, S. Vorster and I.A. Dubery, Anal. Bioanal. Chem., 380, 719 (2004).

23. N.A. Botsoglou, J. Chromatogr. A, 587, 333 (1991).

24. H.L. Kim, M.C. Calhoun and R.D. Stipanovic, Comp. Biochem. Physiol. B: Biochem. Mol. Biol., 113, 417 (1996).

25. R.B. Fombad and M.J. Bryant, Trop. Anim. Health Prod., 36, 295 (2004).

through one extract step and one $\mathrm{C}_{18}$ column clean-up step. This method has proven to be highly reproducible. The minimum detection limit of gossypol was determined to be $10 \mathrm{ng}$ (absolute gossypol).

\section{ACKNOWLEDGEMENTS}

This study has been supported by the Youth Foundation of Poultry Institute of Chinese Agricultural Sciences Academy

26. K.J. Lee, K. Dabrowski, J.H. Blom, S.C. Bai and P.C. Stromberg, J. Anim. Physiol. Anim. Nutr. (Berl.), 86, 201 (2002).

27. K.J. Lee and K. Dabrowski, J. Agric. Food. Chem., 50, 3056 (2002).

28. A. Tse-Yan Lee, Volume 2 Number 1 (2005); http://curezone.com/forums/fm.asp?i=863091 (2005).

29. M.-Z. Wang, D.-F. Wu and Y.-W. Yu, J. Chromatogr. A, 343, 387 (1985). 